\title{
Muralf
}

INTERNACIONAL

\section{Extensão universitária em Relações Internacionais: ditadura e transição à democracia na América do Sul Science outreach in the field of International Relations: dictatorship and transitional justice in South America}

\section{CLARISSA FRANZOI DRI ${ }^{1}$, ANDRESSA CAROLINE MOLINARI DA SILVA ${ }^{2}$ \& MARINA LAZAROTTO DE ANDRADE ${ }^{3}$}

Resumo: Este artigo traz o relato e a discussão de uma iniciativa de extensão universitária e educação popular promovida no âmbito do curso de Relações Internacionais da Universidade Federal de Santa Catarina. Trata-se de analisar a implementação e os resultados do projeto de extensão "Pedro e o Capitão", que levou a discussão sobre ditaduras militares e transição à democracia na América do Sul para escolas públicas de ensino médio da grande Florianópolis. A arte foi o método escolhido para dialogar sobre direitos humanos com os jovens, sendo a encenação da peça teatral "Pedro y el Capitán", de Mario Benedetti, a principal base para a interação. Após análise de conteúdo dos debates com as turmas, conclui-se que o diálogo social sobre o período ditatorial ainda é escasso, o que alimenta a desinformação e opiniões préconcebidas sobre práticas de violência de Estado.
Recebido em:

30 de Julho de 2016

Received on:

July 30, 2016

Aceito em:

15 de Setembro de 2017

Accepted on:

September 15, 2017

DOI:10.12957/rmi.2016.24898

Palavras-chave: Transição democrática. América do Sul. Extensão universitária.

Abstract: This paper reports and discusses an initiative of social interaction and popular education organized within the undergraduate career of International Relations of Federal University of Santa Catarina. It analyzes the implementation and the results of the project "Pedro and the captain", which discussed military dictatorships and democratic transition in South America in secondary public schools in Florianopolis. Art served as a method for human rights dialogue with students, for the play "Pedro y el Capitán", by Mario Benedetti, was the main basis for interaction. The content analysis of debates among student groups reveals that social dialogue in Brazil on the authoritarian period is still rare, which accounts for lack of information and pre-conceived opinions on State violence.

Keywords: Child-soldier; DDR; Sierra Leone.

\footnotetext{
${ }^{1}$ Doutora em Ciência Política pelo Instituto de Estudos Políticos da Universidade de Bordeaux, França. Professora Adjunta da Universidade Federal de Santa Catarina. Endereço para correspondência: UFSC - Departamento de Economia e Relações Internacionais, Campus Universitário, Trindade, Florianópolis, SC, CEP: 88040-970. E-mail: clarissa.dri@ufsc.br

${ }^{2}$ Mestranda do Programa de Pós-Graduação em Relações Internacionais da Universidade Federal de Santa Catarina (UFSC).

${ }^{3}$ Graduada em Relações Internacionais pela Universidade Federal de Santa Catarina (UFSC).
} 


\section{Introdução}

Como trabalhar com extensão universitária nos cursos de Relações Internacionais? Os conteúdos voltados sobretudo às relações entre atores na esfera internacional desafiam a interação entre universidade $\mathrm{e}$ sociedade estabelecida na Constituição Federal brasileira (artigo 207 Constituição Federal 1988). Enquanto cursos como Direito e Medicina organizam tradicionalmente iniciativas de assessoria jurídica universitária popular e projetos de difusão de informações em saúde, a extensão universitária em Relações Internacionais ainda busca caminhos de consolidação e desenvolvimento. Um exemplo são os importantes projetos em andamento em algumas universidades brasileiras, baseados em simulações de organizações internacionais e consultoria para órgãos estatais e organizações não governamentais.

Este artigo busca contribuir para a reflexão sobre o uso da extensão universitária como instrumento de formação para a cidadania dos futuros diplomatas e operadores das Relações Internacionais, trazendo o relato e a discussão de uma iniciativa promovida no âmbito do curso de Relações Internacionais da Universidade Federal de Santa Catarina (UFSC). Trata-se de analisar a implementação e os resultados do projeto de extensão "Pedro e o Capitão" (2012-2014), que levou a discussão sobre ditaduras militares e transição à democracia na América do Sul para escolas públicas de ensino médio da grande Florianópolis. A arte foi o método escolhido para dialogar sobre direitos humanos com os jovens, sendo a encenação da peça teatral "Pedro y el Capitán", do uruguaio Mario Benedetti, a principal base para a interação. Apresentam-se a seguir os fundamentos teóricos da iniciativa, os detalhes da execução do projeto e a análise da transcrição de quatro debates orais conduzidos com os estudantes.

\section{Justiça de transição na educação popular}

Os anos 2000 e 2010 marcam uma nova etapa no processo de transição à democracia nos países sul-americanos. Depois de alguns anos de silêncio relativo, as sociedades começam a reexaminar os fatos acontecidos durante os períodos ditatoriais de 1960 a 1980 . No momento em que a sociedade brasileira ainda se pergunta quais são os significados de uma Comissão Nacional da Verdade (2011) e o que fazer com seu relatório final (2014), cabe inclusive à universidade o papel de fomentar a 


\section{Muralf}

INTERNACIONAL
Mural Internacional

V. 7 | N. 2

JUL-DEZ 2016 reflexão crítica sobre esse período de violência de Estado e sistemática violação dos direitos humanos. À comunidade acadêmica de Relações Internacionais, cabe principalmente a discussão sobre o caráter regional desses regimes que atingiram a América do Sul como um movimento coletivo, a comparação com processos ditatoriais em outros continentes e a investigação sobre os impactos internacionais de uma transição inconclusa.

A literatura identifica em geral cinco principais eixos característicos da justiça de transição, que pode ser definida como a concepção de justiça associada a períodos de mudança política, caracterizada pelas respostas legais que confrontam os erros de regimes repressivos precedentes (Teitel 2013, p. 69). Em momentos políticos de transformação, o direito deve manter a ordem enquanto permite as mudanças em prol dos direitos humanos e da democracia. $\mathrm{O}$ conhecimento da verdade, o resgate e a construção da memória, a punição dos responsáveis por abusos, a reparação moral e financeira das vítimas e as reformas institucionais que garantam normas e práticas democráticas no novo regime são pilares essenciais nesse processo ${ }^{4}$.

${ }^{4}$ Para uma discussão desses eixos e seus formuladores, veja Quinalha 2013, p. 136-153.
No Brasil, as ações da Comissão de Anistia (2002) em memória e reparação são emblemáticas ${ }^{5}$, tanto como é a Lei de Acesso à Informação (2011) que enfrenta sérias resistências na consolidação da transparência institucional. Em países como Argentina, Chile e Uruguai, o debate está mais avançado e alternativas de punição dos violadores de direitos humanos já foram colocadas em prática, com claro impacto positivo nos sistemas democráticos (Sikkink e Walling 2007, p. 427; Skaar, 2015). No âmbito local, Santa Catarina foi palco de diferentes lutas operárias e estudantis, indígenas e camponesas, contra o regime autoritário (Brancher e Lohn, 2014).

Considerando os impactos sociais e políticos diretos dessa temática, as iniciativas de extensão universitária não podem ficar à margem. Extensão é conceituada como "o processo educativo, cultural e científico que articula o ensino e a pesquisa de forma indissociável e viabiliza a relação transformadora entre universidade e sociedade. A extensão é uma via de mão-dupla, com trânsito assegurado à comunidade acadêmica, que encontrará, na sociedade, a oportunidade de elaboração da práxis de um

\footnotetext{
5 Para um detalhamento dessas ações, veja Da Silva Filho
} 2015, p. 51-80. 
conhecimento acadêmico. No retorno à Universidade, docentes e discentes trarão um aprendizado que, submetido à reflexão teórica, será acrescido àquele conhecimento" (Rede Nacional de Extensão 1998, p. 5). A extensão baseia-se, portanto, na ideia de educação popular (Freire 1977; Freire 1996), que destaca a necessária troca de saberes e experiências entre os vários atores envolvidos, todos considerados sujeitos do processo e responsáveis pela produção de diagnósticos científicos resultantes do confronto com a realidade brasileira e regional.

\section{Projeto Pedro e o Capitão}

O projeto Pedro e o Capitão foi concebido no final de 2012 como a primeira iniciativa de extensão do Oirã, grupo de pesquisa e extensão que se formava no seio do curso de Relações Internacionais da UFSC com o intuito de estudar processos de cooperação transnacional na América Latina ${ }^{6}$. O projeto buscou discutir a temática dos

\footnotetext{
${ }^{6}$ Participaram do projeto Pedro e o Capitão os seguintes membros do Oirã: Andressa Molinari, Marina de Andrade, Deborah Abud, Elisa Espíndola, Gabriel Dauer, Matheus Rachadel, Tiago Pittas, Rafael Cruz, Tamara de Lima, Luiza Helena Virgílio, Eveline Maduro, Felipe Souza, Carolina Ferrari, Louise da Silva, Juliana Batista, Isabel Britez, Laís da Palma e Athena Bastos. Jefferson Viana, Ademar Pozzatti Junior, Maria Luiza Sumienski, Jorge Robles e Camila Kuhn colaboraram com o projeto. A peça foi dirigida por Wellington Bauer. A coordenação ficou a cargo de Clarissa Dri e Leticia Albuquerque. O projeto teve apoio da Secretaria de Cultura, Pró-Reitoria de Extensão, Centro Socioeconômico e Centro de Ciências Jurídicas da UFSC.
}

regimes ditatoriais que ocorreram na América do Sul durante a Guerra Fria. Destacando a importância da transição democrática para a consolidação das instituições e o respeito aos direitos humanos, Pedro e o Capitão uniu a arte e a oralidade como ferramentas de intervenção social.

O projeto foi dividido em quatro etapas: a preparação, a materialização, as saídas da universidade e a avaliação das práticas no retorno à universidade. Durante a fase de preparação, no início de 2013, o grupo realizou a leitura coletiva da peça, escrita em 1979, e leituras de capacitação teórica. A capacitação visava proporcionar conhecimento e debate no grupo acerca da história das ditaduras na América do Sul e do processo de transição à democracia, com análises baseadas nos critérios de verdade, memória e justiça. A peça desdobra-se através do diálogo entre um torturado, Pedro, e seu torturador, o Capitão. O texto pode se enquadrar, em tempo e espaço, em qualquer ditadura cívico-militar latinoamericana. O diálogo é interrompido somente pelas seções de tortura, que não são descritas no texto, mas inseridas pelo autor de modo subliminar pela mudança da condição física e psicológica das personagens após cada cena. Todos os diálogos acontecem durante $o$ interrogatório de Pedro, 


\section{Muralf}

INTERNACIONAL

militante político que foi capturado. Nas cenas finais, Pedro está imóvel e muito debilitado quando o Capitão reinicia o interrogatório. Contudo, no decorrer do diálogo, Pedro fortalece-se e denuncia ao Capitão suas ações e as consequências inevitáveis da violência sobre o ser humano que a comete.

A etapa da materialização refletiu de modo mais claro o marco da interdisciplinaridade proposto pelo projeto. Os alunos de Relações Internacionais traduziram a peça do espanhol para o português e, com o auxílio e direção de um estudante do curso de Artes Cênicas, a peça foi adaptada para enquadrar mais personagens. Seu texto foi reduzido e moldado à faixa etária do público-alvo (estudantes secundaristas). Além disso, o cenário foi adaptado e simplificado, de modo a poder ser reproduzido em diferentes salas de aula e auditórios. Utilizou-se apenas uma cadeira, lanternas e som, além do figurino laranja do prisioneiro e preto dos soldados. Os ensaios introduziram os estudantes de Relações Internacionais na experiência de palco, de modo que o conhecimento pudesse ser trocado com a comunidade também de forma oral e corporal. Ainda nesse momento, iniciou-se a seleção das escolas públicas a serem visitadas e o contato com professores e direção para relato do
Mural Internacional

V. 7 | N. 2

JUL-DEZ 2016

projeto. Priorizaram-se escolas da periferia da grande Florianópolis, em bairros como Rio Tavares, Monte Verde, Ribeirão da Ilha, Rio Vermelho e cidades como São José e Palhoça, por dois motivos principais. Em primeiro lugar, as instituições escolhidas em geral recebem pouca ou nenhuma intervenção das universidades locais, pelo que esse diálogo também visava levar informações sobre os cursos e oportunidades acadêmicas aos estudantes secundaristas. Em segundo lugar, tratava-se de proporcionar aos alunos de Relações Internacionais, futuros tomadores de decisão e operadores do tema, o contato com realidades diferentes da classe média intelectual universitária.

Após uma primeira exibição em forma de leitura dramática da peça na UFSC, o grupo começou as apresentações nas escolas no segundo semestre de 2013, o que continuou durante todo o ano de 2014. No total, 25 apresentações foram realizadas, sempre seguidas de debate (média de duas ou três intervenções por mês), totalizando um público direto estimado em 2000 pessoas. Cada apresentação era um desafio diferente e o grupo confrontava-se com dificuldades de acesso e transporte, necessidade de maleabilidade dos materiais de intervenção, precariedade das instalações escolares, opiniões 
controversas nos debates e entusiasmo por parte de alguns professores e alunos em participar do projeto. Por fim, no momento do retorno à universidade, o grupo, em seus encontros após cada apresentação, debatia os pontos principais da peça, além de resgatar as questões levantadas no debate. Dessa forma, cada participante colocava suas impressões sobre a intervenção na escola e um panorama sobre as informações previamente disponíveis aos estudantes da escola visitada era construído. Com base nesses diagnósticos coletivos, o plano para a próxima atividade era traçado. Esses momentos foram essenciais para um balanço interno do papel da extensão universitária, ao mesmo tempo em que o debate acerca da justiça de transição acontecia dentro da universidade.

“Os torturadores não podem ser julgados, mas isso não é justo" (Estudante 1)

Dos mais de 20 debates realizados pelo grupo após a encenação, quatro foram gravados e transcritos para análise neste artigo. Outros seis debates foram objeto de anotações de campo no momento em que ocorriam. A condução do debate pelos estudantes da UFSC foi dividida em três partes: impressões sobre a peça, conhecimento acerca das ditaduras cívico-militares na América do Sul e reflexão sobre proteção dos direitos humanos e liberdade de expressão e opinião. Em primeiro lugar, a fala nos debates revela a capacidade da peça de prender a atenção dos alunos, que relatavam surpresa com as insinuações de tortura e interpretações criativas sobre a posição das personagens e o final da história. "Tem bastante sentimento, a gente consegue sentir bastante do que o Pedro sente" (Estudante 2). "No final, acontece com o capitão o que tinha acontecido com o Pedro no início" (Estudante 3). "O Pedro não morre por causa do ideal dele, o ideal continua" (Estudante 4). "O capitão morre. Como ele não conseguiu a informação do Pedro, o superior do capitão mata ele" (Estudante 5).

$\mathrm{Na}$ segunda parte do debate, surgiam manifestações diversificadas sobre os fatos históricos vinculados aos regimes militares sul-americanos, mesmo o brasileiro. O período e as características do regime ainda são fluidos e indeterminados para a maioria dos estudantes-alvo do projeto, que situam com alguma dificuldade esse autoritarismo no pós-Segunda Guerra Mundial. Isso demonstra o grande caminho que as iniciativas de memória ainda precisam percorrer, inclusive nos currículos escolares da disciplina de História. A terceira parte, sempre a mais controversa, demonstrava 


\section{Muralf}

INTERNACIONAL

frequentemente uma defesa, por parte dos alunos, das práticas de tortura como necessárias à manutenção da ordem ou à elucidação de crimes. "Eles fizeram alguma coisa para ser torturados, de graça não foi" (Estudante 6). "[Se pode ser torturado] depende. Aí isso vai depender do crime que a pessoa cometeu" (Estudante 7). Esse discurso impressiona ainda mais por ser uma opinião comum em meios sociais de baixa renda, dos quais são oriundos grande parte dos presidiários da região. A violência de Estado também é justificada devido à obediência militar e à hierarquia: "mas aqueles que torturavam também poderiam ser torturados se eles não torturassem aquela pessoa, não poderiam?" (Estudante 8). No decorrer do debate, após pontuações dos estudantes, dos membros do Oirã e dos próprios professores da escola, surgiam opiniões contrárias, atestando que "o que mais teve foi inocente que era torturado e eles nem sabiam o que estava acontecendo" (Estudante 9); "tem lugares ainda, países, não me lembro quais agora, que ainda existe pena de morte. Como saber se a pessoa era mesmo culpada? E se ela era inocente?" (Estudante 10). Um dos estudantes teve coragem de cantar uma música (funk) composta por ele: "Vou falar as quatro coisas que todo ditador gosta: censura, dinheiro, tortura e repressão" (Estudante 11).
Mural Internacional

V. 7 | N. 2

JUL-DEZ 2016
Sobre o golpe de 1964, alguns estudantes relatavam a necessidade de evitar uma ditadura comunista, embora isso ficasse controverso nas próprias falas:

"Oirã: O que era o comunismo para os militares, para quem deu o golpe?

Aluno: Era ameaça.

Oirã: Ameaça do quê? O que é que eles poderiam fazer?

Aluna: Perder dinheiro" (Estudante 12).

A midiatização das ações da Comissão Nacional da Verdade e das denúncias do Ministério Público Federal contra agentes de Estado que violaram direitos humanos teve alguma influência nas informações trazidas pelos estudantes. As opiniões majoritárias eram no sentido da importância do resgate da memória e da ineficácia da punição, considerada como revanchismo e desacompanhada da reflexão sobre seu impacto coletivo no sistema político. Em duas escolas, ouviram-se relatos impressionantes e emocionados de professores e alunos sobre envolvimento de familiares com as práticas de tortura no exército ou na luta contra a ditadura. Ficou evidente a ausência de um lócus de diálogo público sobre esse período, que ainda é um tabu mesmo em instituições de ensino e entre docentes e discentes que se encontram 
cotidianamente. Os fatos relativos à ditadura militar no Brasil ainda pertencem à esfera privada, e mesmo no seio das famílias foi relatada uma dificuldade de comunicação sobre esses eventos, que ainda remetem ao medo, à vergonha e ao desconhecido.

“O meu avô na década de 1970, ele também foi preso, torturado, a gente ficou com vigia na porta durante muito tempo, porque ele foi o primeiro balonista aqui da América do Sul, ele trouxe o balonismo para cá e, na época, a Aeronáutica acusou ele de espionagem, não tinha nada a ver, nada a ver. Então falaram que ele estava invadindo o espaço aéreo e, realmente, ele sumiu, a gente ficou sem notícias durante cinco anos, seis anos, mas tinha gente direto na porta do apartamento onde a gente morava e a gente ficou um bom tempo sem falar da ditadura, do vô, inclusive a gente pensou que tinham liquidado com ele, mas ele foi encontrado depois de um tempão, super judiado... foi extremamente torturado, né?! Por uma desconfiança que não tinha nada a ver; como se ele estivesse invadindo o espaço da Aeronáutica, espionando, passando coisa para o comunismo e ele não estava nem aí se era comunismo, capitalismo... realmente, era uma coisa muito violenta, né?" (Professor 1).
"Os museus que eu conheço eu fui com minha escola, eu fui, não com essa, eu fui com o meu colégio; eu não fui 'ah, pô, que dia bom para ir pra o museu'. $\mathrm{Eu}$ acho que essa lição deveria ser passada muito mais na educação, que os professores e assim, olhe, sinceramente, eu estou no terceiro ano do Ensino Médio, segundo semestre, já quase acabando o ano, quase acabando o Ensino Médio e é a primeira vez que eu estou estudando ditadura do Brasil no colégio. Eu passei minha vida escolar inteira escutando assim, olhe: 'A ditadura é ruim e mataram gente, acabou'. Ah, mas o que aconteceu? O que foi? Ou algo assim, sabe?! Eu acho que isso devia ser inserido no plano curricular, sei lá, talvez não desde a primeira série, mas..." (Estudante 13).

$\mathrm{Na}$ fase final da discussão, perguntados sobre o fim da ditadura e as falhas do atual sistema democrático, muitos alunos aproximavam a falta de liberdade e o abuso de poder por parte do Estado no período ditatorial com eventos atuais. "Eu acho que eles se acham superiores que a gente, porque acham que podem fazer o que quiser. Eu estava parada e eles estavam construindo a rua de Canasvieiras, e chegou um policial e começou a chutar os carros, achava que estava mandando ali, fazendo o que quisesse com a rua. Ele acha que só porque eles estão no poder eles podem 


\section{Muralf}

INTERNACIONAL
Mural Internacional

V. 7 | N. 2

JUL-DEZ 2016 fazer qualquer coisa com a gente. A gente é povo, a gente tem direito de se expressar da melhor maneira. Ele estava ali pra guiar os carros pra não ter acidente, e eles acabaram abusando do poder" (Estudante 14). "Quando eu não posso escolher o meu cabelo, e outra pessoa se sente incomodada com a minha cor ou como eu me visto, também é um tipo de ditadura. Eu me sinto torturada, por exemplo. E eu, particularmente, pensei que isso não ocorresse mais, mas eu passei por uma situação dessas. Quando as pessoas não respeitam a minha escolha, a minha orientação sexual. Daí sempre vem uma pessoa que fala 'Ah não, eu não tenho problema com homossexual, mas não gosto que sente do meu lado'. Tem muito disso, e é uma forma de ditadura também. É um padrão criado pela sociedade, em que as pessoas devem ser magras, de cabelo liso, e ter esse perfil. Se você foge disso não é mais correto. É diferente, não é aceito" (Estudante 15).

Mesmo que muitos estudantes não tenham mudado de opinião a respeito da violação dos direitos humanos sob o período autoritário, o projeto conseguiu levantar esse debate. Isso ficava claro pelas conversas dos alunos depois da intervenção da turma e no horário do intervalo, e pela procura aos membros do Oirã em veículos como e-mail e redes sociais. A partir de um momento no projeto, professores de outras escolas contatavam o grupo solicitando apresentações em suas instituições. Esse debate passou a ser conhecido nos meios escolares de Florianópolis e demandado pelos educadores, demonstrando a eficácia da interação universidade-comunidade para suscitar reflexão crítica.

\section{Conclusão}

Pedro e o Capitão é um projeto interdisciplinar complexo que mescla arte, cultura, política, extensão universitária, princípios de educação popular e iniciativas de pesquisa. $\mathrm{O}$ projeto exigiu grande dedicação de seus membros, que em pouco tempo e com poucos recursos montaram e apresentaram uma peça de teatro encenada por estudantes de áreas não vinculadas às artes. Os estudantes, de diferentes períodos da graduação e com o auxílio de um graduando do curso de Artes Cênicas, traduziram, adaptaram, conceberam cenário, figurino, sonorização e iluminação, além de tornarem-se atores em um processo desafiador. Do ponto de vista dos graduandos, as dificuldades encontradas não se detiveram somente nos prazos exíguos para a preparação da peça e tempos de ensaios semanais curtos. Referiram-se também à dinâmica da criação artística e as inseguranças 
relacionadas à falta de experiência dos membros com o teatro e sua recente aproximação como um grupo, que produzia, por vezes, reservas com relação à atuação e à condução do debate e desarmonia na intervenção. Do ponto de vista dos coordenadores, os desafios foram mais relacionados à logística e à comunicação com os dirigentes escolares. A burocracia da universidade pública torna o processo de compra de materiais e contratação de transporte muito vagaroso, por vezes impossível. A isso se soma a burocracia própria das escolas públicas e a necessidade de adaptação das atividades escolares para recepção dos universitários. Nesse tópico, talvez um planejamento anual conjunto entre escola e universidade, com diálogo entre professores e demonstração de interesses temáticos e metodológicos para diferentes projetos, permitisse uma melhor organização das atividades.

Apesar dos receios iniciais, o contato das disciplinas tradicionais com instrumentos artísticos e a interação entre universidade e comunidade foram os pontos altos sempre destacados pelos participantes, demonstrando que a universidade pode ter um papel relevante não apenas na pesquisa sobre autoritarismos e proteção internacional dos direitos humanos, mas também na extensão universitária abordando esses temas. O exercício baseou-se em não somente estudar e entender esses temas a partir de um ponto de vista multidisciplinar, mas também em estimular outros estudantes a construir conhecimento a partir desses aprendizados. A abordagem teatral potencializou visivelmente o interesse e a atenção do público-alvo. Essa experiência permitiu aos membros do Oirã realizarem reflexões interdisciplinares a partir de suas próprias vivências e a desenvolverem habilidades de assimilação e associação de eventos e fenômenos em seus diversos níveis de articulação. Desse modo, os estudantes de Relações Internacionais podem auxiliar na construção da reflexão coletiva sobre temas políticos e sociais que atingem toda a região ou diferentes Estados. Além do ensino e da pesquisa, a extensão universitária constitui-se em um pilar fundamental na formação cívica e cidadã dos futuros profissionais sobre o país, os interesses e as ideias que eles estarão representando internacionalmente. 


\section{Muralf}

INTERNACIONAL

Mural Internacional

V. $7 \mid$ N. 2

JUL-DEZ 2016

\section{Referências}

\section{Bibliografia}

Brancher, A. L.; Lohn, R. (2014). Histórias na ditadura: Santa Catarina (19641985). Florianópolis: EDUFSC.

Da Silva Filho, J. C. (2015). Justiça de transição da ditadura civil-militar ao debate justransicional. Porto Alegre: Livraria do Advogado.

Freire, P. (1977). Extensão ou comunicação? 3. ed. Rio de Janeiro: Paz e Terra, 1977.

Freire, P. (1996). Pedagogia da autonomia: saberes necessários à prática educativa. 30. ed. São Paulo: Paz e Terra.

Quinalha, R. (2013). Justiça de transição: contornos de um conceito. São Paulo: Outras Expressões.

Rede Nacional de Extensão (1998). Plano Nacional de Extensão Universitária. Natal: Fórum de Pró-Reitores de Extensão das Universidades Públicas Brasileiras.

Sikkink, K.; Walling, C. (2007). "The Impact of Human Rights Trials in Latin America", Journal of Peace Research, 44(4), pp.427-445.

Skaar, E. et al. (2015). Reconceptualizing Transitional Justice: The Latin American Experience. London: Routledge.

Teitel, R. (2003). “Transitional Justice Genealogy”, Harvard Human Rights Journal, v. 16, pp. 69-94.

\section{Depoimentos}

Estudante 1: Estudante da Escola Estadual Laura Lima, Florianópolis, em debate no dia 18/10/2013.

Estudante 2: Estudante da Escola Estadual Dom Jaime Câmara, Florianópolis, em debate no dia 30/10/2013.

Estudante 3: Estudante da Escola Estadual Dom Jaime Câmara, Florianópolis, em debate no dia 04/11/2013. 


\section{0}

Estudante 4: Estudante da Escola Estadual Dom Jaime Câmara, Florianópolis, em debate no dia 04/11/2013.

Estudante 5: Estudante da Escola Estadual Jacob Anderle, Florianópolis, em debate no dia 24/06/2014.

Estudante 6: Estudante do Colégio Militar Feliciano Nunes Pires, Florianópolis, em debate no dia 11/09/2014.

Estudante 7: Estudante da Escola Estadual Presidente Roosevelt, Florianópolis, em debate no dia 29/04/2014.

Estudante 8: Estudante do Colégio Militar Feliciano Nunes Pires, Florianópolis, em debate no dia 11/09/2014.

Estudante 9: Estudante do Colégio Militar Feliciano Nunes Pires, Florianópolis, em debate no dia 11/09/2014.

Estudante 10: Estudante da Escola Estadual Presidente Roosevelt, Florianópolis, em debate no dia 29/04/2014.

Estudante 11: Estudante do Colégio Militar Feliciano Nunes Pires, Florianópolis, em debate no dia 11/09/2014.

Estudante 12: Estudante do Colégio Militar Feliciano Nunes Pires, Florianópolis, em debate no dia 11/09/2014.

Estudante 13: Estudante do Colégio Militar Feliciano Nunes Pires, Florianópolis, em debate no dia 11/09/2014.

Estudante 14: Estudante da Escola Estadual Jacob Anderle, Florianópolis, em debate no dia 24/06/2014.

Estudante 15: Estudante da Escola Estadual Jacob Anderle, Florianópolis, em debate no dia 24/06/2014.

Professor 1: Professor do Colégio Militar Feliciano Nunes Pires, Florianópolis, em debate no dia 11/09/2014. 